gay lifestyles so they can understand (and treat) gay patients better.

Chapters have titles that, mostly, promise more than they deliver. And careless writing does not help: "Oriel... argued such variables as compulsive promiscuity are... due to emotional insecurity or personality disorders" is on page 16. On page 17 the same sentence appears, but this time Oriel "suggested" it. Equally some of the medicine is suspect: "the rectal mucosa is in many places only one cell thick" and "oroanal contact... provides an excellent route of transmission for... proctitis", for instance.

Ross falls into the trap of concluding that certain psychosocial variables are causally related to various venereal diseases or sexual activities. In reality they are merely associations. And unfortunately some of these associations themselves are questionable-is $p>0 \cdot 1$ significant, for example?

Survey work is about figures, yet this book gets them wrong time and again. It is also littered with spelling errors and has been very amateurishly typeset. Sloppily written, shoddily typeset, and printed on the worst quality paper, this book does the author a great disservice. And that is a shame, because the hypotheses underlying the work are most interesting.

\section{David Goldmeier} Peter Holmes
Sexually transmitted diseases. By D Goldmeier and S Barton. (Pp 187; £7.95.) Berlin: Springer Verlag, 1987.

This new volume on sexually transmitted diseases (STD) examines the subject in the form of multiple choice questions and aide memoires, such as limericks, poems, and a mnemonic. It makes a pleasant change from the burgeoning issue of new books on STD, and the authors are to be congratulated on dreaming up 122 different stem questions. As well as covering STD, other topics encountered by those working in genitourinary medicine are included, such as colposcopy, psychological and sexual problems, and basic immunology.

The true or false format used is unavoidably rigid and, although the authors attempt to qualify their answers when appropriate, there is a tendency to consider issues as black or white without the interesting shades of grey. This is particularly relevant in the final section on case histories, which the authors appreciate as they invite comments so that they "can be persuaded by" their critics" "viewpoints". The response to this challenge will be interesting. Open debate on clinical matters may be contentious but is also healthy. There are, however, several minor inconsistencies in the text that are irritating. For example, ampi- cillin or amoxycillin is advocated in the treatment of acute prostatitis but later on it is stated that ampicillin does not penetrate into the prostate gland. The sensitivity of the Gram stain in the diagnosis of gonorrhoea in women is given as $40-50 \%$ in one question and $60 \%$ in another. Respected authorities would question that the intrauterine contraceptive device has not been implicated as an important risk factor for the development of bacterial vaginosis and that vulval warts only have an incubation period of up to 90 days. The use of a three week course of oral acyclovir to prevent recurrence of genital herpes may be admirable but, at a cost of $£ 84$ and with little measurable benefit, would not find favour in hospital budgets. These are small points, and others found may act as a stimulus to the reader.

This book will undoubtedly be of most value as last minute revision for candidates sitting the diploma in venereology examination. It should also be available in all genitourinary medical clinics so that junior staff can assess their knowledge and consultants can rediscover the full extent of their speciality.

R S Pattman

matovenereology, and the remaining 40 are on the history of medicine. A total of 35 of his papers were published in medical journals abroad.

Professor Lejman was an expert in venereology with particular reference to microbiology and clinical syphilology. He took a great interest in the biomorphology of Trepohema pallidum, and he investigated its ultrastructure and distribution in early secondary syphilis. He also examined the influence of antibiotics on treponemes in man and rabbits, which lead to the involutional changes of $T$ pallidum - that is, to their lysis or to the formation of granular forms and argentophilic globular bodies (cysts). He described the histopathological picture of late serpiginous syphilis and the phenomenon of the subdued febrile Herxheimer reaction after the first injection of penicillin in patients reinfected with syphilis. Moreover, he gave much consideration to patients representing either particular clinical features or an atypical course of syphilitic infection, such as syphilitic balanitis of 